\title{
Safety of anti- rheumatic drugs in men trying to conceive: a systematic review and analysis of published evidence.
}

Maria Mouyis*, Julia Flint*, Ian Giles.

*joint first authors.

\section{Disclosure statement}

The authors declare no conflicts of interest

\section{Funding statement}

This work was not funded.

\section{Abstract:}

There is limited evidence relating to the impact of disease modifying anti-rheumatic drugs (DMARDs) upon male fertility and peri-conception paternal exposure in men with rheumatic disease. Therefore, we conducted a systematic review of available evidence to update information on this subject and guide paternal counselling. A systematic search of PubMed and Embase was carried out up to September 2017, to find relevant peer-reviewed papers, using keywords for fertility / spermatogenesis / conception, men, and disease modifying or biologic drugs commonly prescribed in patients with rheumatic disease. The search yielded 724 papers, and the titles/abstracts were screened independently by 2 authors, duplicates removed and 233 potentially relevant papers selected for full text review. A total of 84 papers were included in the final analysis which covered the impact on fertility of over 611 male exposures to relevant drugs, and over 5986 pregnancies conceived during paternal exposure to (or within 3 months of stopping) these drugs. Aside from the known adverse impact of cyclophosphamide and sulfasalazine on spermatogenesis, overall there was no firm evidence of harm to fertility or pregnancy outcomes with paternal exposure to anti-TNF therapies, abatacept, rituximab, azathioprine, cyclosporine $A$, hydroxychloroquine, leflunomide, methotrexate or mycophenolate mofetil. There was no evidence found pertaining to the effects of male exposure to IVIG, tacrolimus, golimumab, anakinra or belimumab on fertility or pregnancy outcomes. These results provide further reassurance as to the safety of many DMARDs for men trying to conceive and will be useful when counselling men about risks of anti-rheumatic drugs to fertility and pregnancies, and following accidental conception.

\section{Introduction}

There is little evidence relating to the safety of disease modifying anti-rheumatic drugs (DMARDS) in men with inflammatory rheumatic disease wishing to conceive. The 2016 British Society of Rheumatology (BSR) guidelines on prescribing DMARDs in pregnancy concluded that "Data relating to the impact of paternal exposure to these drugs (both fertility and male-mediated teratogenicity) [are] particularly limited, and further research in these areas is urgently required." $(1,2)$. Other guidelines in this area are limited to maternal exposure (3). 
The organisation of teratology information specialists (OTIS) defines paternal exposure as "anything the father of the baby is exposed to before or during his partner's pregnancy". In rheumatic disease, traditional and biologic DMARDS are used long term to control disease activity, and prevent complications and disability.

In women, effective disease control improves pregnancy outcomes (4) with the BSR guidelines identifying rheumatic drugs which are safe to continue during pregnancy and breastfeeding. In men, there is some evidence identifying a relationship between rheumatic disease activity and fertility (57). Active inflammatory disease may negatively affect sperm quality hence fertility (8-10). It is unknown whether good control of paternal inflammatory disease at conception may also improve pregnancy outcomes (11). Although medication safety concerns often arise, they are based mainly on animal or in vitro experimental data, as relevant human evidence is often lacking. During drug development and clinical trials, pregnancy following male or female exposure is contraindicated and relevant data slowly accumulates through reporting of accidental pregnancy exposure, postmarketing surveillance and registry data recording pregnancy exposure (12). Clinicians often ask female patients about pregnancy planning, but this questioning is less routine with male patients, compounding the lack of understanding and guidance.

To improve knowledge amongst patients and clinicians, we conducted a systematic review using all peer-reviewed published human data to try and answer two main questions for each selected drug: 'Does the drug affect male fertility?' and 'Is peri-conception paternal exposure to the drug associated with adverse pregnancy outcomes?'

\section{Methods}

A systematic search of PubMed and Embase up to September 2017 was conducted using guidelines of preferred reporting items for systematic reviews and meta-analyses (PRISMA) (13). The keywords related to male fertility / conception, and DMARD or biologic drugs commonly used in rheumatic disease, and are shown in box 1.

\section{Inclusion criteria}

Relevant papers described exposure of male patients to specified drugs (for rheumatic or nonrheumatic indications), and reported either subsequent fertility or infertility (measured by seminal analysis, or ability to conceive), or pregnancy outcomes in patients' partners.

\section{Exclusion criteria}

Reviews, animal and in-vitro studies, and non-English language papers were excluded. Letters (except where they included unpublished original data) and non-peer reviewed abstracts were excluded (due to the risk of overlap with subsequent papers). Papers describing pre/peri-pubertal exposure only and studies of cancer chemotherapy or transplantation were also excluded (due to differing dosing regimens and underlying disease processes).

\section{Study selection}

Titles and abstracts were independently reviewed by two authors, and relevant papers selected for full text review. Any disagreement was resolved by discussion. Reference lists of relevant reviews and included papers were checked for additional original papers.

A data extraction sheet was designed and piloted using 3 papers. The final version included study design and methodology, number and description of men or pregnancies exposed to each drug, number and description of any control group, and outcomes relating to fertility or exposed pregnancies. Study limitations were also documented. 
For each drug, the outcomes were reviewed, limitations considered and results summarised as shown. This qualitative approach was taken as specific data for each drug was often limited, with inconsistent and incomplete outcome reporting. The quality of evidence available for each drug was assessed using the GRADE methodology (14).

\section{Results}

The initial search yielded 724 papers, and 84 papers were finally selected for analysis (figure 1). These studies reported the impact on fertility of over 611 male exposures to relevant drugs, and over 5986 pregnancies conceived during paternal exposure to (or within 3 months of stopping) these drugs. 35 papers had a comparator or control group. Results for the individual drugs are shown in Table 1.

\section{Biologic DMARDs}

\section{Abatacept}

Abatacept is a soluble fusion protein of human IgG1 to CTLA4, which is a T-cell surface receptor. The CTLA4 binds to the $B$ cell thus preventing $B$ cell activation, and T cell mediated cytokine release. It is used in the treatment of RA. No specific recommendation was made in the BSR guidelines due to a lack of published evidence.

Our search found a recent cohort study of 10 peri-conception paternal exposures to abatacept (15), resulting in 9 live births and 1 elective abortion, with no congenital abnormalities or foetal deaths. Therefore, no concerns were raised from this limited number of peri-conception paternal exposures.

\section{Anti TNF}

TNF -alpha inhibitors, principally etanercept, adalimumab, infliximab, golimumab and certolizumab are used to treat Rheumatoid Arthritis (RA) and other inflammatory rheumatic diseases when other drugs fail. The majority of human paternal exposure data however, is derived from inflammatory bowel disease (IBD) exposures. These findings are summarised in Table 1.

\section{Fertility}

A total of 34 male exposures to adalimumab, 9 exposures to etanercept and 84 exposures to infliximab were found describing the effect on male fertility. Most papers raised no concerns. Only two case reports noted a co-incident decrease in sperm quality with anti-TNF $(16,17)$, and two small studies ( $n=13$ exposures) described a non-significant correlation between infliximab and reduced sperm motility or abnormal morphology $(18,19)$. There were however, multiple confounding factors / limitations to these studies. In addition, findings from four of these studies ( $n=51$ exposures) reported that improved control of inflammatory disease with anti-TNF therapy was associated with improved seminal parameters $(6,7,20,21)$.

\section{Pregnancy outcomes}

There were 47 peri-conception paternal exposures to etanercept (table 1) reported. It was not possible to extrapolate specific pregnancy outcomes following paternal exposure but no concerns were raised. A total of 88 paternal exposures to infliximab were reported, with no concerns about pregnancy outcomes raised. Where specified there were 74/78 live births (the 2 losses with further details available were during the $1^{\text {st }}$ trimester with other risk factors). A total of $63 / 67$ had no malformations or were described as 'healthy'. In addition, three cohort studies $(7,22,23)$ reported 
432 peri-conceptional paternal exposures to a variety of anti-TNF medications (adalimumab, etanercept, certolizumab and infliximab), reporting no association with adverse pregnancy outcomes or congenital malformations.

Two large cohort studies $(24,25)$ that included 10 peri-conceptual paternal exposures to adalimumab did not specify pregnancy outcomes nor report any concerns. The malformation rate in a cohort of $(n=1198)$ men prescribed DMARDs, including $(n=6)$ adalimumab, was approximately $3.7 \%$, which the authors quoted within 'western countries' population rate of $2.4-4 \%$ (24).

In a worldwide online survey (26) of 33 paternal exposures to certolizumab there were: 27 live births; 4 miscarriages; 1 induced abortion; and 1 stillbirth, which does not appear to be significantly different from pregnancy outcomes in the general population of the USA, where this study was based.

Therefore, no specific concerns were identified regarding the safety of paternal exposure to antiTNF, in line with BSR guidelines that infliximab, adalimumab and etanercept are consistent with paternal exposure. Since publication of the BSR guidelines, a reassuring body of evidence is accumulating, particularly with infliximab.

\section{Rituximab}

Rituximab is used for the treatment of refractory RA, SLE and vasculitis. This search did not identify any additional data to that described in the BSR guideline of registry data (27) reporting pregnancy outcomes in partners of 16 males with conception ranging from two weeks to one year following rituximab infusion. Of 22 pregnancies, outcome data was available in only 11, and included 7 live births (with only 3 gestational ages reported as full term), 2 miscarriages, and 2 ongoing pregnancies. Therefore, the evidence base has not expanded to alter the BSR recommendation that, based on limited evidence, RTX is compatible with paternal exposure.

\section{Disease Modifying anti-Rheumatic drugs (DMARDs)}

\section{Azathioprine}

Azathioprine is an immunosuppressive drug mostly used to treat SLE and inflammatory myositis. It interferes with purine metabolism and inhibits both DNA and RNA synthesis.

\section{Fertility}

The included studies (table 1 ) describe $>76$ male exposures to azathioprine with respect to male fertility. One case series reported teratospermia in a patient on azathioprine (28). A cohort study reported a trend towards higher rates of infertility amongst 30 patients on azathioprine, but the incidence of infertility did not reach statistical significance compared with 54 unexposed disease (IBD) controls (25). The remaining 6 studies ( $>45$ exposures) $(7,29-33)$ drew no association between azathioprine and abnormal sperm parameters.

\section{Pregnancy outcomes}

There were $>3248$ peri-conception paternal exposures to azathioprine (Table 2). Although one prescription database study reported a slightly higher malformation rate in exposed $(7.4 \%$ or 4 out of $n=52)$ compared with unexposed $(4.1 \%, n=57195)$ pregnancies (exposure presumed based on prescription being filed), all of these conceptions occurred more than 9 months after the prescription was last filed by the father. None of the 19 exposures documented within 3 months of conception resulted in a congenital malformation (34). A more recent study by the same authors found no increase in congenital malformations, preterm birth or small for gestational age amongst ( $n=699$ ) fathers exposed to azathioprine/6-MP within 3 months of conception, compared to 
$(n=1,012,624)$ controls (35). Another large population based cohort study looked at longer term outcomes in 735 children following paternal exposure to azathioprine or 6-mercaptopurine, (with $n=1,056,524$ controls), and concluded that there was no negative impact of paternal preconception use of azathioprine on selected outcomes (malignancies, autism spectrum disorders/schizophrenia/psychosis, and attention deficit hyperactivity disorder)(36). No other papers raised concern about adverse pregnancy outcomes following paternal exposure.

Although the transplantation literature was excluded from our search, a recent population based study linked two comprehensive national registries of all solid organ transplants (the Norwegian Transplant Registry) and all births (the Medical Birth Registry of Norway) to identify the impact of paternal post-transplant immunosuppression on birth outcomes. This commonly includes azathioprine, and reassuringly the authors found no significant difference in the rate of major malformations, preterm delivery or small for gestational age (SGA) babies between 4614 deliveries (4650 infants) to fathers pre-transplant, 474 deliveries (492 infants) to fathers post transplant (likely to be on immunosuppression) and 2511206 deliveries in the general population. Interestingly there was an increased risk of preeclampsia associated with fathers with transplants on immunosuppression, which remains unexplained.(37)

These findings are in keeping with the current BSR guidelines suggesting compatibility of paternal exposure to azathioprine with pregnancy, and are additionally reassuring with respect to male fertility.

\section{Ciclosporin}

Ciclosporin is a calcineurin inhibitor. It inhibits $T$ cell activity by preventing the activation of calinuerin by binding to the cyclophilin protein and is used in RA, psoriatic arthritis and SLE. Four cohort studies reported on male fertility $(n>2)$ or peri-conception paternal $(n>248)$ exposure to ciclosporin $(30,32,38,39)$ for rheumatic disease.

Fertility

Of 35 patients with SLE who had lower sperm volume, count, motility and normal morphology when compared to healthy controls, two were on ciclosporin (30). A cohort of Behçet's syndrome patients (both male and female, 20/88 of whom were on ciclosporin) did not have appreciably reduced fertility (32).

\section{Pregnancy outcomes}

One man treated with infliximab and ciclosporin fathered a healthy child (38). In the Behçet's cohort, the average number of children, miscarriages, terminations and ectopic pregnancies were not significantly different from controls (32), but specific outcomes following ciclosporin paternal exposure are not reported. A Danish registry study reported 247 children who were conceived whilst the father was on ciclosporin. Outcomes included 15 cases of pre-term births, 16 congenital abnormalities and 19 cases of low birth weight. These authors however did not show an association between paternal exposure to ciclosporin and an increased risk of congenital abnormalities (Adjusted OR 0.82)(39)

The BSR guidelines included data from paternal exposure in renal transplant recipients, thus results from a larger number of paternal exposures $(n>254)$ were considered (1). This evidence was also of low quality but raised no specific concerns with regards to male fertility or paternal exposure. More recently, a large population based study described above (under azathioprine) reported reassuring 
birth outcomes in babies born to fathers on immunosuppression following solid organ transplant, which commonly includes cyclosporin or tacrolimus.(37)

\section{Cyclophoshamide}

Cyclophosphamide is used for the treatment of severe SLE or vasculitis. It is known to be teratogenic following maternal exposure, and gonadotoxic in men and women.

\section{Fertility}

The included studies are shown in table 1 . Amongst $>103$ men, there was almost universal reporting of reduced sperm counts, including azoospermia and teratospermia, during or after cyclophosphamide treatment. The sperm counts can fall within the first 3 weeks, but normally after 4 months of treatment with cyclophoshpamide. All studies however, that followed patients after treatment cessation reported some (though not universal) improvement in sperm counts over time, $(29,40-43)$ with a mean recovery time of 31 months reported in one paper(40). Five successful conceptions were reported (40-42).

\section{Pregnancy outcomes}

Peri-conception paternal exposure is rare due to the impact on male fertility, and the only reported data relates to historical, rather than peri-conception paternal exposure. One cohort study examined pregnancy outcomes for fathers who had been treated with cycophosphamide (44) and reported 13 exposures. This study included 2 men with 7 pregnancy losses between them prior to 4 live births (both exposed to cyclophosphamide $>10$ years prior), as well as one man with 2 live births (exposed $<1 y$ r prior to first conception). This finding could reflect a greater interest of fathers to respond to a survey following such pregnancy morbidity (which may have had other e.g. maternal causes) rather than a truly increased rate of pregnancy loss due to historical paternal cyclophosphamide exposure. There were no studies of paternal exposure within 3 months of conception.

The BSR guideline concludes that paternal exposure to cyclophosphamide is not recommended due to its adverse impact on seminal parameters which may affect fertility. We found that in the event of pregnancy following paternal exposure to cyclophosphamide there remains limited data on pregnancy outcomes.

\section{Hydroxychloroquine}

In the BSR guidelines, this anti-malarial is considered safe both for women to use during pregnancy and breastfeeding, and for peri-conception paternal exposure.

\section{Fertility}

A case report in a potential father treated for malaria with hydroxychloroquine was diagnosed with azoospermia and teratospermia that persisted for 17 months, although malaria itself was considered a major confounding factor (45).

\section{Pregnancy Outcomes}

There were 13 peri-conception paternal exposures to hydroxychloroquine (table 1 ). In the cohort study (24), one of the 12 babies was born with a malformation, which is too small a sample size to draw conclusions, but the authors raised no concerns. The case series (46) included one paternal exposure, resulting in a live birth.

Data is surprisingly limited for such a commonly prescribed drug, but no other papers were identified which raised concerns about paternal exposure. The BSR guidelines, using the same evidence base, state that men should not be discouraged from taking HCQ while trying to conceive. 


\section{Leflunomide}

Leflunomide is a pyrimidine synthesis inhibitor that works by inhibiting dihydroorotate dehydrogenase. It is used in RA and other autoimmune conditions. It is teratogenic in animals but human data from the BSR guideline for accidental peri-conceptual/first-trimester exposure in $(n=111)$ women who stop the medication and undergo an urgent washout with cholestyramine revealed reassuring pregnancy outcomes (1).

\section{Pregnancy outcomes}

There is little evidence to assess safety (table 2). The case series (47) included one paternal exposure to leflunomide from 6 months pre-conception throughout pregnancy (with no barrier contraception) resulting in a healthy baby. One cohort reported another healthy baby (15). The other cohort study did not report specific outcomes, but the malformation rate amongst a cohort of 1198 men prescribed 'anti-rheumatics' (including 1 exposure to leflunomide), was within the quoted population rate of 2-4\% (24). Based on a similarly limited number of exposures $(n=2)$ BSR guidelines state that leflunomide may be compatible with paternal exposure, and the only exposure subsequently reported resulted in a healthy live birth, but further studies to confirm compatibility are warranted.

\section{Methotrexate}

Methotrexate (MTX) is used to treat various forms of inflammatory arthritis and may also be used in other autoimmune rheumatic diseases. It inhibits dihydrofolate reductase, an enzyme used in activating dihydrofolate to tetrahydrofolate. The reduction in folate synthesis interferes with DNA synthesis.

\section{Fertility}

48 male MTX exposures were included (table 1). There were two case reports of oligospermia associated with MTX: One resolved on stopping methotrexate and recurred when restarted (48); the other was unaffected by stopping methotrexate (49). The other 5 papers ( $n=46$ exposures) however, all concluded that there was no impact of methotrexate on fertility.

One case series of 26 exposed men to methotrexate had their semen examined using radioactive phosphorus for testicular histology, and spermatogenic function. As above there was no negative impact of male spermatogenesis(50).

\section{Pregnancy outcomes}

Included studies (table 2) reported 1511 peri-conception paternal exposures. One cohort study reported 3 periconception exposures to methotrexate (amongst 2 fathers) and included one 1st trimester therapeutic abortion due to hydrocephalia (38). Another 17 studies ( $n=1508$ exposed pregnancies) however, did not find a link between paternal methotrexate exposure and adverse pregnancy outcomes or congenital malformations. Where outcomes were specified, there were 264 live births to 34 pregnancy losses (including spontaneous and elective abortions, but early pregnancy losses may not be accurately captured by all studies), and in studies where congenital malformations were reported, there was a total of 967 'healthy' babies with 78 congenital malformations. The two largest studies to assess this issue raised no concerns about the malformation rate: One reported 127 live births including 4 babies with congenital malformations (3.2\%), which was a lower rate than in the unexposed group (3.4\%, odds ratio of 0.93$)(51)$. The other study reported 72 congenital abnormalities amongst 864 live births, and the rate was not significantly elevated compared to the control group (odds ratio of $1.12(0.87-1.43)$ )(39). In this study, the odds ratios for low birth weight and preterm birth were $0.86(0.62-1.19)$ and $1.02(0.74-1.42)$ respectively. After correcting for 
potential confounders, the authors concluded that paternal methotrexate exposure conferred no additional risk to pregnancy outcomes. Another large population based cohort study looked at longer term outcomes in 209 children following paternal exposure to methotrexate (with $\mathrm{n}=1,056,524$ controls). This study concluded that there was no negative impact of paternal preconception use of methotrexate on selected outcomes (malignancies, autism spectrum disorders /schizophrenia/ psychosis, and attention deficit hyperactivity disorder) (36).

Following the reassuring BSR guidelines that, based on limited evidence, low-dose MTX may be compatible with paternal exposure, further evidence is accumulating (with an additional 1248 reported exposures) to support this view.

MMF

Mycophenelate Mofetil (MMF) is used predominantly in the treatment of SLE and as an immunosuppressive agent in transplant patients. It affects B cell function by inhibiting the enzyme inosine monophosphate dehydrogenase.

Fertility

One cohort study of male SLE patients, included 4 men on MMF (30). All 35 SLE patients had sperm abnormalities when compared to controls, but those on MMF were in the less abnormal group and only teratospermia was noted in this group as opposed to asthenospermia seen in the other groups. No concerns were raised about MMF contributing to impaired fertility.

Pregnancy outcomes

Two cohort studies included 38 peri-conception paternal exposures to $\operatorname{MMF}(15,39)$ resulting in one healthy live birth in one study(15), and a congenital malformation rate of $<3 / 37$ (odds ratio of 0.7 (0.17-2.91) in the other (39). The larger study also showed no significantly increased risk of low birth weight or pre-term birth.

The BSR guidelines included data from paternal exposure in renal transplant recipients, and so results from a larger number of paternal exposures $(n=72)$ were considered (1). This evidence was also of low quality, but raised no specific concerns, and concluded that based on very limited evidence, MMF is compatible with paternal exposure. Since publication of the guideline, another large population based study of 230 immunosuppressed renal transplanted men, who fathered 350 children ( $n=155$ exposed to mycophenolate) also concluded that paternal exposure to MMF did not increase the risk of adverse birth outcomes in children fathered by male kidney transplanted patients (52). In addition, a large population based study described above (under azathioprine) reported reassuring birth outcomes in babies born to fathers on immunosuppression following solid organ transplant, which commonly includes cyclosporin.(37)

\section{Sulfasalazine}

Sulfasalazine is used in the treatment of both Rheumatoid arthritis and Psoriatic arthritis. It breaks down into 5-aminosalicylic acid (5-ASA) and the sulfapyridine moiety, which may potentially impair spermatogenesis (53). The risk may also be linked to sulfasalazine antagonising folic acid metabolism, which is reduced by concomitant folic acid supplementation (54). 
Fertility

The included 31 studies are shown in table 1 and describe $>250$ exposed men. However, only two studies $(7,32)$ included patients with rheumatic disease, the remainder covering IBD treatment or healthy controls.

Almost all studies noted poor sperm parameters in patients treated with sulfasalazine, and in most cases these resolved within 3 months of stopping treatment, but the real impact on conception rate during treatment is difficult to extrapolate. These studies reported a total of 37 pregnancies following cessation of sulfasalazine.

Pregnancy Outcomes

It must be noted however that infertility is not universal, as a total of $>284$ conceptions were reported having been conceived during paternal exposure to sulfasalazine.

Although many of the specific pregnancy outcomes are not reported, only 3 of the 12 studies raised any concerns. One IBD cohort reported a spontaneous abortion in a twin pregnancy following paternal exposure to smoking, azathioprine and sulfasalazine, but it is unclear how many of the 7 live births in this cohort were also on sulfasalazine (31). A second IBD cohort included 4 live births and 1 stillbirth (55). Finally, a survey of IBD patients reported a higher proportion of congenital malformations amongst parents on sulfasalazine than those not on sulfasalazine (14/17 children with malformations were following paternal exposure to sulfasalazine). In this study however, the total number of paternal exposures to sulfasalazine are not shown, nor are pregnancy outcomes reported for exposed versus unexposed pregnancies. In addition, the study design relied on selfreported medication use and outcomes and is likely subject to a degree of recall bias (56). In contrast, 9 of the 12 studies ( 278 exposures) reported no adverse pregnancy outcomes attributed to sulfasalazine exposure. Where outcomes were specified, there were $82 / 84$ healthy babies with only 2 malformations, and where pregnancy losses were also reported, there were 26/32 live births.

Therefore, a negative impact of SSZ on spermatogenesis is not universal and overall pregnancy outcomes following paternal conception are reassuring. These findings support the BSR guidance that sulfasalazine should only be stopped in potential fathers if conception is delayed for more than 12 months when other causes of infertility should then be excluded, as the risks of stopping the medication must be weighed up against the risk of harm.

\section{Other medications}

No studies were identified which addressed any potential impact of Golimumab, Tocilizumab, Anakinra, Belimumab ,iv immunoglobulin , tacrolimus, tofacitinib, baracitinib, secukinumab, ustekinumab and apremilast on male fertility or pregnancy outcomes following paternal exposure.

Glucocorticoids and non-steroidal anti-inflammatory drugs were beyond the scope of this review, but were included in parts one and two of the recent BSR guidelines respectively(1) (2). Limited low quality evidence of paternal exposure to corticosteroids and non-steroidals did not raise concerns about birth outcomes.

\section{Discussion}

In this systematic review, we found largely reassuring evidence for paternal exposure to various DMARDs. Since the BSR guidelines, new evidence is emerging relating to paternal exposure to abatacept as well as further reassuring evidence relating to paternal exposure to anti-TNF, MTX, MMF, ciclosporin and AZA. The impact of anti-rheumatic drugs on male fertility was not covered in 
the BSR guideline, and in this review, we also found largely reassuring evidence, aside from the known adverse impact of sulfasalazine on spermatogenesis.

The health of a man wishing to conceive may impact on male fertility and ability to conceive, as well as the success of the pregnancy and health of the child. In rheumatic disease, medication is required to control disease activity. Various medications however, may have direct effects upon developing spermatozoa, and/or their chemical transfer in seminal fluid by unprotected sexual intercourse after conception could theoretically affect the developing foetus (although drug levels are likely to be insignificant) (57). Safety of medication is therefore an important concern of men with rheumatic disease who wish to conceive, but unfortunately data in this area is very limited and low in quality.

Much of the concern about peri-conception safety stems from animal or in-vitro data, with limited applicability to humans. In addition, it is difficult to extrapolate even the results of human sperm analysis, which is only a surrogate marker of fertility (or chance of real-life conception) in exposed patients. Reports of peri-conception paternal exposure are limited by publication and recall bias as well as a lack of reporting of confounding factors, such as paternal health, concomitant medications, maternal health and pregnancy risk factors. Adverse pregnancy outcomes also occur at a variable rate in the general population (usually quoted $2-4 \%$ ), and may be multifactorial. The impact of paternal exposure to medications, above all the other factors contributing to the birth outcomes, is very difficult to ascertain. A small shift in this baseline rate of pregnancy or obstetric morbidity or mortality would be difficult to detect and so vast study numbers would be needed to 'prove' the safety of these medications. Some of the best evidence comes from population based registry studies, but these are limited by loss to follow up and un-reported pregnancy outcomes. Higher quality evidence in this area is therefore sorely needed.

The European Medicines Agency (EMA) is reliant on human pregnancy data from pre- and postauthorisation studies, as well as spontaneous case reports on both adverse outcomes and normal outcomes. Healthcare professionals are therefore encouraged to report peri-conception DMARD exposures, whether outcomes are normal or not via the yellow card system. The report should ideally include maternal, paternal and neonatal information (12). Paternal as well as maternal exposures to medications can also be reported to the UK teratology information service (UKTIS) via a downloadable form (58). However, a national pregnancy registry for anti-rheumatic drugs, similar to those which exist for anti-epileptics, would be invaluable in achieving this aim.

Any perceived or real risks of continuing medications peri-conception need to be balanced against the risk of disease flares and high dose rescue therapy. Much of our evidence of the negative impact of uncontrolled inflammatory disease on fertility, thus conception, comes from studies on paternal exposure in IBD $(8,11)$. We did however, identify some evidence to suggest that the same process may occur in rheumatic disease For example, patients with active SLE were found to have abnormal and reduced spermatogenesis when compared to controls (30).

This review of the available human in-vivo data allows some reassuring trends to be noted with regards to pregnancy outcomes in the general population. OTIS estimates that a woman has a background risk of 3-5\% of having a baby with a birth defect (59). We did not find any evidence to suggest a consistently higher risk of birth defects following paternal exposure to any of the antirheumatic drugs we considered in this review. In addition, none of the studies we identified raised significant concerns regarding pregnancy losses, prematurity or low birth weight.

Paternal DMARD use may affect conception in different ways. Cyclophosphamide and sulfasalazine (via the sulfapyridine moiety) both appear to affect spermatogenesis to different degrees. Whilst 
sulfasalazine is associated with worsening seminal parameters, there are also numerous reports of conception whilst on sulfasalazine, and seminal parameters appear to resolve within 3 months. Therefore, it is also important to remember to look for other causes of infertility and consider the potential adverse impact of stopping medications such as SSZ, that are controlling rheumatic disease activity, as loss of disease control may impair conception for various reasons.

Such resolution post cyclophosphamide however, may take longer or be irreversible. Studies of cyclophosphamide use in cancer chemotherapy also suggest sperm DNA damage after treatment. Therefore, male patients undergoing treatment are usually counselled to avoid conception for a period after treatment, and semen cryopreservation may be recommended as an option. Although it remains a physically and psychologically demanding process, the expansion of assisted reproductive technologies over recent decades permits fertility preservation in many cases (60) This process of freezing sperm prior to treatment allows a chance for future fertility. The sperm is frozen using various cryprotectants (vitrification) (61). When the sperm is needed the thawing process is initiated. This is considered a safe procedure and in long term follow up of people conceived from frozen sperm no significant defects have been identified in comparison to the general population (62). Where medications are prescribed which may affect fertility of both male and female patients, it is crucial to discuss this in advance, with referral to discuss fertility preservation as appropriate (63) $(64,65)$.

Overall the data on the impact of peri-conception paternal exposure to anti-rheumatic drugs remains limited and so further research in this area is urgently required to provide men wishing to conceive with more certainty, or quantify the risk to fertility or pregnancy. Unbiased prospective reporting of any maternal or paternal exposures to anti-rheumatic drugs, followed by reporting of the pregnancy outcome when available would help to achieve this goal. For now, we hope that the results presented in this review will be useful when counselling men about risks of anti-rheumatic drugs to fertility and pregnancies, and following accidental conception.

\section{Acknowledgements}

The authors would like to thank Michael Kendall for his help with the literature search 
Table 1: Results of Systematic Study of Paternal Exposure in men trying to conceive.

\begin{tabular}{|c|c|c|c|c|c|c|}
\hline Drug & $\begin{array}{l}\text { Studies of } \\
\text { fertility / } \\
\text { conception } \\
\text { (n=total male } \\
\text { exposures) }\end{array}$ & \begin{tabular}{|l|} 
Studies of \\
pregnancy \\
outcomes \\
( $\mathrm{n}=$ total \\
pregnancies \\
exposed) \\
\end{tabular} & Impact on male fertility & $\begin{array}{l}\text { GRADE of } \\
\text { evidence }\end{array}$ & $\begin{array}{l}\text { Impact of paternal exposure on } \\
\text { pregnancy outcome }\end{array}$ & $\begin{array}{l}\text { GRADE of } \\
\text { Evidence }\end{array}$ \\
\hline \multicolumn{7}{|l|}{ Biologic Drugs } \\
\hline $\begin{array}{l}\text { Anti-TNF: } \\
\text { adalimumab }\end{array}$ & $\begin{array}{l}4 \text { cohort }(6,7, \\
20,66), \\
2 \text { case report } \\
(16,17), \\
1 \text { case series } \\
(33)(n=34)\end{array}$ & $\begin{array}{l}2 \text { cohort }(24, \\
25), \\
(n=10)\end{array}$ & \multirow{4}{*}{$\begin{array}{l}\text { Improved control of inflammatory } \\
\text { disease with anti-TNF therapy was } \\
\text { generally associated with improved } \\
\text { semen parameters. There were } 2 \\
\text { case reports noting a co-incident } \\
\text { decrease in sperm quality with anti- } \\
\text { TNF therapy, and } 2 \text { small studies (total } \\
13 \text { exposures) suggesting a possible } \\
\text { non-significant link between } \\
\text { infliximab and reduced sperm motility } \\
\text { or abnormal morphology, but there } \\
\text { were multiple confounding factors } \\
\text { and limitations to these studies. }\end{array}$} & \multirow[t]{4}{*}{ Very low } & \multirow[t]{4}{*}{$\begin{array}{l}\text { None of these studies reported } \\
\text { rates of adverse pregnancy } \\
\text { outcomes that were significantly } \\
\text { higher than would be expected. }\end{array}$} & \multirow[t]{4}{*}{ Very low } \\
\hline $\begin{array}{l}\text { Anti TNF: } \\
\text { certolizumab }\end{array}$ & 0 & \begin{tabular}{|l|}
1 case series \\
$(26)(n=33)$ \\
\end{tabular} & & & & \\
\hline Anti TNF: etanercept & $\begin{array}{l}3 \text { cohort }(7, \\
20,66) \\
2 \\
2 \text { case report } \\
(16,21)(n=9)\end{array}$ & \begin{tabular}{|l|}
3 cohort $(24$, \\
$67,68)$, \\
1 case series \\
$(46), 1$ case \\
report $(21)$ \\
$(n=47)$
\end{tabular} & & & & \\
\hline Anti TNF: infliximab & $\begin{array}{l}4 \text { cohort }(7, \\
18,38,66), \\
2 \text { case series } \\
(19,33) \text {, } \\
1 \text { case report } \\
(16)(n=84)\end{array}$ & $\begin{array}{l}7 \text { cohort }(25, \\
38,67-71) \\
2 \text { case series } \\
(46,72) \\
1 \text { case report } \\
(16) \\
(n=88)\end{array}$ & & & & \\
\hline
\end{tabular}




\begin{tabular}{|c|c|c|c|c|c|c|}
\hline Anti TNF: combined & & $\begin{array}{l}3 \text { cohort }(7, \\
22,23)(n=432)\end{array}$ & & & & \\
\hline $\begin{array}{l}\text { Rituximab } \\
\text { No changes }\end{array}$ & 0 & $\begin{array}{l}1 \text { cohort }(27) \\
(n=11)\end{array}$ & No data & $\mathrm{N} / \mathrm{A}$ & $\begin{array}{l}\text { Of the } 11 \text { reported exposures ( } 2 \\
\text { weeks-1year prior to conception), } \\
\text { there were } 2 \text { miscarriages, } 7 \text { live } \\
\text { births and } 2 \text { ongoing pregnancies } \\
\text { at the time of publication. }\end{array}$ & Very low \\
\hline $\begin{array}{l}\text { Abatacept } \\
\text { No changes }\end{array}$ & 0 & $\begin{array}{l}1 \text { cohort }(15) \\
(n=10)\end{array}$ & No data & N/A & $\begin{array}{l}\text { The very limited evidence does } \\
\text { not raise any concerns about peri- } \\
\text { conception paternal exposure }\end{array}$ & Very low \\
\hline \multicolumn{7}{|c|}{ Disease Modifying anti-Rheumatic drugs (DMARDs) } \\
\hline Azathioprine & $\begin{array}{l}6 \text { cohort }(7, \\
25,29-32) \\
2 \text { case series } \\
(28,33)(n>76)\end{array}$ & $\begin{array}{l}12 \text { cohort }(24, \\
25,31,32,34- \\
36,39,67,73- \\
75) \\
1 \text { case series } \\
(46) \\
(n>3248)\end{array}$ & $\begin{array}{l}\text { The majority of studies were } \\
\text { reassuring about the effect of } \\
\text { azathioprine on semen parameters. }\end{array}$ & Very low & $\begin{array}{l}\text { The majority of studies do not } \\
\text { raise a concern regarding } \\
\text { pregnancy outcomes. }\end{array}$ & Very low \\
\hline Ciclosporin A & $\begin{array}{l}2 \text { cohort }(30, \\
32)(n>2)\end{array}$ & $\begin{array}{l}3 \text { cohort }(32, \\
38,39)(n>248)\end{array}$ & $\begin{array}{l}\text { The very limited available evidence } \\
\text { did not suggest an effect of } \\
\text { Ciclosporin A on fertility. }\end{array}$ & Very low & $\begin{array}{l}\text { The limited evidence did not raise } \\
\text { concerns about adverse } \\
\text { pregnancy outcomes (congenital } \\
\text { abnormalities, low birth weight or } \\
\text { prematurity) }\end{array}$ & Very low \\
\hline Cyclophosphamide & $\begin{array}{l}7 \text { cohort }(29, \\
30,32,40,42, \\
76,77) \\
1 \text { case series } \\
(28) \\
1 \text { case report } \\
(41)\end{array}$ & $\begin{array}{l}1 \text { cohort (44) } \\
(n=13)\end{array}$ & $\begin{array}{l}\text { Almost universal reporting of reduced } \\
\text { sperm counts, including azoospermia } \\
\text { and teratospermia, some } \\
\text { improvement reported after cessation } \\
\text { of treatment. }\end{array}$ & Low & $\begin{array}{l}\text { The quality of available evidence } \\
\text { was too limited to draw } \\
\text { conclusions about pregnancy } \\
\text { outcomes following paternal } \\
\text { exposure }\end{array}$ & Very low \\
\hline
\end{tabular}




\begin{tabular}{|c|c|c|c|c|c|c|}
\hline & $\begin{array}{l}1 \mathrm{RCT}(43) \\
\text { (indirect } \\
\text { evidence) } \\
(\mathrm{n}>103)\end{array}$ & & & & & \\
\hline $\begin{array}{l}\text { Hydroxychloroquine } \\
\text { (HCQ) }\end{array}$ & $\begin{array}{l}1 \text { case report } \\
(45) \\
(n=1)\end{array}$ & $\begin{array}{l}1 \text { cohort }(24) \\
1 \text { case series } \\
(46) \\
(n=13)\end{array}$ & $\begin{array}{l}\text { There was only one case report of the } \\
\text { effect of HCQ on fertility, with } \\
\text { multiple confounders. }\end{array}$ & Very low & $\begin{array}{l}\text { The very limited evidence did not } \\
\text { raise concerns about adverse } \\
\text { pregnancy outcomes }\end{array}$ & Very low \\
\hline Leflunomide & & $\begin{array}{l}2 \text { cohort }(15, \\
24) \\
1 \text { case series } \\
(47) \\
(n=3) \\
\end{array}$ & No data & $\mathrm{N} / \mathrm{A}$ & $\begin{array}{l}\text { The very limited evidence did } \\
\text { report any adverse pregnancy } \\
\text { outcomes }\end{array}$ & Very low \\
\hline Methotrexate (MTX) & $\begin{array}{l}4 \text { cohort }(7, \\
29,30,78) \\
1 \text { case series } \\
(50) \\
2 \text { case reports } \\
(48,49) \\
(n=48)\end{array}$ & $\begin{array}{l}13 \text { cohort }(15, \\
22,24,36,38, \\
39,51,67-69, \\
74,75,79) \\
2 \text { case series } \\
(46,80) \\
3 \text { case reports } \\
(81-83) \\
(n=1511)\end{array}$ & $\begin{array}{l}\text { Aside from } 2 \text { case reports of } \\
\text { oligospermia, the other } 5 \text { larger } \\
\text { studies concluded that there was no } \\
\text { impact of MTX on fertility. }\end{array}$ & Very low & $\begin{array}{l}\text { Only one small cohort study } \\
\text { reported a major malformation } \\
\text { amongst the } 3 \text { paternal exposures } \\
\text { to MTX, whereas another } 17 \\
\text { studies ( } n=1508 \text { exposed } \\
\text { pregnancies) did not find a link } \\
\text { between paternal methotrexate } \\
\text { exposure and adverse pregnancy } \\
\text { outcomes or congenital } \\
\text { malformations. }\end{array}$ & Low \\
\hline $\begin{array}{l}\text { Mycophenolate } \\
\text { mofetil (MMF) }\end{array}$ & $\begin{array}{l}1 \text { cohort }(30) \\
(n=4)\end{array}$ & $\begin{array}{l}2 \text { cohorts }(15, \\
39)(n=38)\end{array}$ & $\begin{array}{l}\text { The very limited available evidence } \\
\text { did not suggest an effect of MMF on } \\
\text { fertility. }\end{array}$ & Very low & $\begin{array}{l}\text { The limited evidence did report } \\
\text { any adverse pregnancy outcomes } \\
\text { (congenital abnormalities, low } \\
\text { birth weight or prematurity) }\end{array}$ & Very low \\
\hline $\begin{array}{l}\text { Sulfasalazine } \\
\text { No change }\end{array}$ & $\begin{array}{l}12 \text { cohort }(7, \\
25,31,32,53, \\
55,84-89) \\
8 \text { case series } \\
(90-97)\end{array}$ & $\begin{array}{l}11 \text { cohort }(22, \\
24,25,31,32 \\
53,55,56,70 \\
75,89)\end{array}$ & $\begin{array}{l}\text { The vast majority of data comes from } \\
\text { inflammatory bowel disease patients. } \\
\text { Almost all studies noted poor sperm } \\
\text { parameters in patients treated with } \\
\text { sulfasalazine, but in most cases these }\end{array}$ & Low & $\begin{array}{l}\text { Most studies reported no adverse } \\
\text { pregnancy outcomes attributed to } \\
\text { sulfasalazine exposure. }\end{array}$ & Very low \\
\hline
\end{tabular}




\begin{tabular}{|l|l|l|l|l|l|}
\hline & 9 case reports & 1 case series & resolved on stopping treatment and & & \\
$(98-106)$ & $(97)$ & infertility is not universal. & & \\
2 mechanistic & $(n>284)$ & & & \\
studies (107, & & & & \\
$(108)$ & & & & & \\
\hline
\end{tabular}


Box 1 : Search criteria 
A) Men OR man OR male

OR father* (fathers, fatherhood)

OR patern* (paternal, paternity)

B) DMARD* (DMARD, DMARDS)

OR Antimalarial*

OR Hydroxychloroquine OR chloroquine

OR Anti-rheumatic*

OR Sulfasalazine OR salazopyrin

OR Leflunomide

OR Azathioprine

OR Methotrexate

OR Ciclosporin OR cyclosporin OR cyclosporine

OR Cyclophosphamide

OR Tacrolimus

OR Mycophenolate OR MMF OR Mycophenolic acid

OR intravenous immunoglobulin OR ivig

OR Leflunomide

OR Tacrolimus

OR Gold

OR Penicillamine

OR Biologic* (Biologics, Biological drugs)

OR Anti-TNF OR TNF inhibit* (inhibitor, inhibition)

OR Etanercept OR enbrel

OR Infliximab OR Remicade OR Remsima OR Inflectra

OR Adalimumab OR humira OR Exemptia

OR certolizumab OR Cimzia

OR Golimumab OR simponi

OR Abatacept OR orencia

OR Rituximab OR Rituxan OR MabThera OR Zytux

OR Tocilizumab OR Actemra OR RoActemra

OR anakinra

OR belimumab

OR secukinumab

OR ustekinumab

OR tofacitinib

OR baricitinib

OR apremilast

C) 'spermato*' (Spermatogenesis, spermatozoa)

OR 'sperm' (sperm count)

OR 'fertil*' (fertile and fertility)

OR 'semen*' (semen and seminal fluid)

OR 'conception'

OR 'conceive'

OR pregnancy OR pregnant OR pregnan*

(A) AND (B) AND (C) 


\section{References}

1. Flint J, Panchal S, Hurrell A, van de Venne M, Gayed M, Schreiber K, et al. BSR and BHPR guideline on prescribing drugs in pregnancy and breastfeeding-Part I: standard and biologic disease modifying anti-rheumatic drugs and corticosteroids. Rheumatology. 2016;55(9):1693-7.

2. Flint J, Panchal S, Hurrell A, van de Venne M, Gayed M, Schreiber K, et al. BSR and BHPR guideline on prescribing drugs in pregnancy and breastfeeding-Part II: analgesics and other drugs used in rheumatology practice. Rheumatology. 2016;55(9):1698-702.

3. Gotestam Skorpen C, Hoeltzenbein M, Tincani A, Fischer-Betz R, Elefant E, Chambers C, et al. The EULAR points to consider for use of antirheumatic drugs before pregnancy, and during pregnancy and lactation. Annals of the rheumatic diseases. 2016;75(5):795-810.

4. Lin H-C, Chen S-F, Lin H-C, Chen Y-H. Increased risk of adverse pregnancy outcomes in women with rheumatoid arthritis: a nationwide population-based study. Annals of the rheumatic diseases. 2010;69(4):715-7.

5. Tiseo BC, Cocuzza M, Bonfá E, Srougi M, Clovis A. Male fertility potential alteration in rheumatic diseases: a systematic review. International Brazilian Journal of Urology : official journal of the Brazilian Society of Urology. 2016;42(1):11-21.

6. Ramonda R, Foresta C, Ortolan A, Bertoldo A, Oliviero F, Lorenzin M, et al. Influence of tumor necrosis factor alpha inhibitors on testicular function and semen in spondyloarthritis patients. Fertility and sterility. 2014;101(2):359-65.

7. Villiger PM, Caliezi G, Cottin V, Forger F, Senn A, Ostensen M. Effects of TNF antagonists on sperm characteristics in patients with spondyloarthritis. Annals of the rheumatic diseases.

2010;69(10):1842-4.

8. Palomba S, Sereni G, Falbo A, Beltrami M, Lombardini S, Boni MC, et al. Inflammatory bowel diseases and human reproduction: a comprehensive evidence-based review. World journal of gastroenterology. 2014;20(23):7123-36.

9. Sarkar O, Bahrainwala J, Chandrasekaran S, Kothari S, Mathur PP, Agarwal A. Impact of inflammation on male fertility. Frontiers in bioscience (Elite edition). 2011;3:89-95.

10. Timmer A, Bauer A, Dignass A, Rogler G. Sexual function in persons with inflammatory bowel disease: a survey with matched controls. Clinical gastroenterology and hepatology : the official clinical practice journal of the American Gastroenterological Association. 2007;5(1):87-94.

11. Mahadevan U. Fertility and pregnancy in the patient with inflammatory bowel disease. Gut. 2006;55(8):1198-206.

12. Agency EM. Guideline on the exposure to medicinal products during pregnancy: Need for post-authorisation data 2006 [10/08/2017]. Available from:

http://www.ema.europa.eu/docs/en GB/document library/Regulatory and procedural guideline/ 2009/11/WC500011303.pdf.

13. Liberati A, Altman DG, Tetzlaff J, Mulrow C, Gotzsche PC, loannidis JP, et al. The PRISMA statement for reporting systematic reviews and meta-analyses of studies that evaluate healthcare interventions: explanation and elaboration. Bmj. 2009;339:b2700.

14. Atkins D, Best D, Briss PA, Eccles M, Falck-Ytter Y, Flottorp S, et al. Grading quality of evidence and strength of recommendations. Bmj. 2004;328(7454):1490.

15. Kumar M, Ray L, Vemuri S, Simon TA. Pregnancy outcomes following exposure to abatacept during pregnancy. Semin Arthritis Rheum. 2015;45(3):351-6.

16. Younis S, Rimar D, Slobodin G, Boulman N, Rozenbaum M, Rosner I. Effect of infliximab on male fertility: Comment on the article "Fertility in male patients with seronegative 
spondyloarthropathies treated with infliximab" by Saougou et al., Joint Bone Spine 2013;80, 34-37. Joint, bone, spine : revue du rhumatisme. 2014;81(1):102-3.

17. Wildi LM, Haraoui B. Reversible male infertility under treatment with an anti-TNFalpha agent: a case report. Annals of the rheumatic diseases. 2012;71(3):473-4.

18. Mahadevan U, Terdiman JP, Aron J, Jacobsohn S, Turek P. Infliximab and semen quality in men with inflammatory bowel disease. Inflammatory bowel diseases. 2005;11(4):395-9.

19. Montagna GL, Malesci D, Buono R, Valentini G. Asthenoazoospermia in patients receiving anti-tumour necrosis factor \{alpha\} agents. Annals of the rheumatic diseases. 2005;64(11):1667.

20. Almeida BP, Saad CG, Souza FH, Moraes JC, Nukumizu LA, Viana VS, et al. Testicular Sertoli cell function in ankylosing spondylitis. Clinical rheumatology. 2013;32(7):1075-9.

21. Rezvani A, Ozaras N. Infertility improved by etanercept in ankylosing spondylitis. Indian journal of pharmacology. 2008;40(6):276-7.

22. Wallenius M, Lie E, Daltveit AK, Salvesen KA, Skomsvoll JF, Kalstad S, et al. No excess risks in offspring with paternal preconception exposure to disease-modifying antirheumatic drugs. Arthritis \& rheumatology (Hoboken, NJ). 2015;67(1):296-301.

23. Larsen MD, Friedman S, Magnussen B, Norgard BM. Birth Outcomes in Children Fathered by Men Treated with Anti-TNF-alpha Agents Before Conception. The American journal of gastroenterology. 2016;111(11):1608-13.

24. Viktil KK, Engeland A, Furu K. Outcomes after anti-rheumatic drug use before and during pregnancy: a cohort study among 150,000 pregnant women and expectant fathers. Scandinavian journal of rheumatology. 2012;41(3):196-201.

25. Teruel C, Lopez-San Roman A, Bermejo F, Taxonera C, Perez-Calle JL, Gisbert JP, et al. Outcomes of pregnancies fathered by inflammatory bowel disease patients exposed to thiopurines. The American journal of gastroenterology. 2010;105(9):2003-8.

26. Clowse ME, Wolf DC, Forger F, Cush JJ, Golembesky A, Shaughnessy L, et al. Pregnancy Outcomes in Subjects Exposed to Certolizumab Pegol. The Journal of rheumatology. 2015;42(12):2270-8.

27. Chakravarty EF, Murray ER, Kelman A, Farmer P. Pregnancy outcomes after maternal exposure to rituximab. Blood. 2011;117(5):1499-506.

28. Silva CA, Hallak J, Pasqualotto FF, Barba MF, Saito MI, Kiss MH. Gonadal function in male adolescents and young males with juvenile onset systemic lupus erythematosus. The Journal of rheumatology. 2002;29(9):2000-5.

29. Moraes AJ, Pereira RM, Cocuzza M, Casemiro R, Saito O, Silva CA. Minor sperm abnormalities in young male post-pubertal patients with juvenile dermatomyositis. Brazilian journal of medical and biological research = Revista brasileira de pesquisas medicas e biologicas. 2008;41(12):1142-7.

30. Soares PM, Borba EF, Bonfa E, Hallak J, Correa AL, Silva CA. Gonad evaluation in male systemic lupus erythematosus. Arthritis and rheumatism. 2007;56(7):2352-61.

31. Dejaco C, Mittermaier C, Reinisch W, Gasche C, Waldhoer T, Strohmer H, et al. Azathioprine treatment and male fertility in inflammatory bowel disease. Gastroenterology. 2001;121(5):1048-53. 32. Uzunaslan D, Saygin C, Hatemi G, Tascilar K, Yazici H. No appreciable decrease in fertility in Behcet's syndrome. Rheumatology. 2014;53(5):828-33.

33. Valer P, Algaba A, Santos D, Fuentes ME, Nieto E, Gisbert JP, et al. Evaluation of the Quality of Semen and Sexual Function in Men with Inflammatory Bowel Disease. Inflammatory bowel diseases. 2017;23(7):1144-53.

34. Norgard B, Pedersen L, Jacobsen J, Rasmussen SN, Sorensen HT. The risk of congenital abnormalities in children fathered by men treated with azathioprine or mercaptopurine before conception. Alimentary pharmacology \& therapeutics. 2004;19(6):679-85.

35. Norgard BM, Magnussen B, Larsen MD, Friedman S. Reassuring results on birth outcomes in children fathered by men treated with azathioprine/6-mercaptopurine within 3 months before conception: a nationwide cohort study. Gut. 2017;66(10):1761-6. 
36. Friedman $S$, Larsen MD, Magnussen B, Jolving LR, de Silva $P$, Norgard BM. Paternal use of azathioprine/6-mercaptopurine or methotrexate within 3 months before conception and long-term health outcomes in the offspring-A nationwide cohort study. Reproductive toxicology (Elmsford, NY). 2017;73:196-200.

37. Morken NH, Diaz-Garcia C, Reisaeter AV, Foss A, Leivestad T, Geiran O, et al. Obstetric and neonatal outcome of pregnancies fathered by males on immunosuppression after solid organ transplantation. American journal of transplantation : official journal of the American Society of Transplantation and the American Society of Transplant Surgeons. 2015;15(6):1666-73.

38. Saougou I, Markatseli TE, Papagoras C, Kaltsonoudis E, Voulgari PV, Drosos AA. Fertility in male patients with seronegative spondyloarthropathies treated with infliximab. Joint, bone, spine : revue du rhumatisme. 2013;80(1):34-7.

39. Egeberg A, Gislason GH, Nast A. Birth Outcomes in Children Fathered by Men Treated with Immunosuppressant Drugs before Conception\&\#x2014;A Danish Population-Based Cohort Study. Journal of Investigative Dermatology.137(8):1790-2.

40. Buchanan JD, Fairley KF, Barrie JU. Return of spermatogenesis after stopping cyclophosphamide therapy. Lancet. 1975;2(7926):156-7.

41. Blake DA, Heller RH, Hsu SH, Schacter BZ. Return of fertility in a patient with cyclophosphamide-induced azoospermia. The Johns Hopkins medical journal. 1976;139(1):20-2.

42. Fairley KF, Barrie JU, Johnson W. Sterility and testicular atrophy related to cyclophosphamide therapy. Lancet. 1972;1(7750):568-9.

43. Masala A, Faedda R, Alagna S, Satta A, Chiarelli G, Rovasio PP, et al. Use of testosterone to prevent cyclophosphamide-induced azoospermia. Annals of internal medicine. 1997;126(4):292-5.

44. Clowse ME, Richeson RL, Pieper C, Merkel PA. Pregnancy outcomes among patients with vasculitis. Arthritis care \& research. 2013;65(8):1370-4.

45. Singer R, Segenreich E, Sagiv M, Shohat B, Livni E, Bartoov B, et al. Decreased semen quality in a male infected with malaria. International journal of andrology. 1987;10(5):685-9.

46. Beghin D, Cournot MP, Vauzelle C, Elefant E. Paternal exposure to methotrexate and pregnancy outcomes. The Journal of rheumatology. 2011;38(4):628-32.

47. De Santis M, Straface G, Cavaliere A, Carducci B, Caruso A. Paternal and maternal exposure to leflunomide: pregnancy and neonatal outcome. Annals of the rheumatic diseases. 2005;64(7):1096-7.

48. Sussman A, Leonard JM. Psoriasis, methotrexate, and oligospermia. Archives of dermatology. 1980;116(2):215-7.

49. Pandhi D, Gupta R, Singal A. Gynaecomastia with oligospermia: an unusual complication of low-dose methotrexate for pustular psoriasis. Clinical and experimental dermatology. 2006;31(1):138-40.

50. El-Beheiry A, El-Mansy E, Kamel N, Salama N. Methotrexate and fertility in men. Archives of andrology. 1979;3(2):177-9.

51. Eck LK, Jensen TB, Mastrogiannis D, Torp-Pedersen A, Askaa B, Nielsen TK, et al. Risk of Adverse Pregnancy Outcome After Paternal Exposure to Methotrexate Within 90 Days Before Pregnancy. Obstetrics \& Gynecology. 2017;129(4):707-14.

52. Midtvedt K, Bergan S, Reisaeter AV, Vikse BE, Asberg A. Exposure to Mycophenolate and Fatherhood. Transplantation. 2017;101(7):e214-e7.

53. O'Morain C, Smethurst P, Dore CJ, Levi AJ. Reversible male infertility due to sulphasalazine: studies in man and rat. Gut. 1984;25(10):1078-84.

54. Hernandez-Diaz S, Werler MM, Walker AM, Mitchell AA. Folic acid antagonists during pregnancy and the risk of birth defects. The New England journal of medicine. 2000;343(22):160814.

55. Birnie GG, McLeod TI, Watkinson G. Incidence of sulphasalazine-induced male infertility. Gut. 1981;22(6):452-5. 
56. Moody GA, Probert C, Jayanthi V, Mayberry JF. The effects of chronic ill health and treatment with sulphasalazine on fertility amongst men and women with inflammatory bowel disease in Leicestershire. International journal of colorectal disease. 1997;12(4):220-4.

57. Klemmt L, Scialli AR. The transport of chemicals in semen. Birth Defects Research Part B: Developmental and Reproductive Toxicology. 2005;74(2):119-31.

58. Service UTI. UKTIS pregnancy reporting form [Available from:

http://www.uktis.org/docs/paternal\%20exposures.pdf and

http://www.uktis.org/UKTIS reporting form.pdf.

59. (OTIS) OoTIS. [Available from: https://mothertobaby.org/fact-sheets/paternal-exposurespregnancy/pdf/.

60. Brezina PR, Kutteh WH, Bailey AP, Ding J, Ke RW, Klosky JL. Fertility preservation in the age of assisted reproductive technologies. Obstetrics and gynecology clinics of North America.

2015;42(1):39-54.

61. Vutyavanich T, Piromlertamorn W, Nunta S. Rapid freezing versus slow programmable freezing of human spermatozoa. Fertility and sterility. 2010;93(6):1921-8.

62. Kopeika J, Thornhill A, Khalaf Y. The effect of cryopreservation on the genome of gametes and embryos: principles of cryobiology and critical appraisal of the evidence. Human reproduction update. 2015;21(2):209-27.

63. Nahata L, Sivaraman V, Quinn GP. Fertility counseling and preservation practices in youth with lupus and vasculitis undergoing gonadotoxic therapy. Fertility and sterility. 2016;106(6):1470-4.

64. Gajjar R, Miller SD, Meyers KE, Ginsberg JP. Fertility preservation in patients receiving cyclophosphamide therapy for renal disease. Pediatric nephrology (Berlin, Germany).

2015;30(7):1099-106.

65. Mersereau J, Dooley MA. Gonadal failure with cyclophosphamide therapy for lupus nephritis: advances in fertility preservation. Rheumatic diseases clinics of North America. 2010;36(1):99-108, viii.

66. Micu MC, Micu R, Surd S, Girlovanu M, Bolboaca SD, Ostensen M. TNF-alpha inhibitors do not impair sperm quality in males with ankylosing spondylitis after short-term or long-term treatment. Rheumatology. 2014;53(7):1250-5.

67. Lee CY, Jin C, Mata AM, Tanaka T, Einarson A, Koren G. A pilot study of paternal drug exposure: the Motherisk experience. Reproductive toxicology (Elmsford, NY). 2010;29(3):353-60.

68. Ostensen $\mathrm{M}$, von Esebeck $\mathrm{M}$, Villiger PM. Therapy with immunosuppressive drugs and biological agents and use of contraception in patients with rheumatic disease. The Journal of rheumatology. 2007;34(6):1266-9.

69. Paschou S, Voulgari PV, Vrabie IG, Saougou IG, Drosos AA. Fertility and reproduction in male patients with ankylosing spondylitis treated with infliximab. The Journal of rheumatology.

2009;36(2):351-4.

70. Sato A, Naganuma M, Asakura K, Nishiwaki Y, Yajima T, Hisamatsu T, et al. Conception outcomes and opinions about pregnancy for men with inflammatory bowel disease. Journal of Crohn's \& colitis. 2010;4(2):183-8.

71. Lichtenstein GR, Feagan BG, Cohen RD, Salzberg BA, Diamond RH, Price S, et al. Serious infection and mortality in patients with Crohn's disease: more than 5 years of follow-up in the TREAT registry. The American journal of gastroenterology. 2012;107(9):1409-22.

72. Katz JA, Antoni C, Keenan GF, Smith DE, Jacobs SJ, Lichtenstein GR. Outcome of pregnancy in women receiving infliximab for the treatment of Crohn's disease and rheumatoid arthritis. The American journal of gastroenterology. 2004;99(12):2385-92.

73. Hoeltzenbein M, Weber-Schoendorfer C, Borisch C, Allignol A, Meister R, Schaefer C. Pregnancy outcome after paternal exposure to azathioprine/6-mercaptopurine. Reproductive toxicology (Elmsford, NY). 2012;34(3):364-9.

74. Hellwig K, Haghikia A, Gold R. Parenthood and immunomodulation in patients with multiple sclerosis. Journal of neurology. 2010;257(4):580-3. 
75. Engeland A, Bjorge T, Daltveit AK, Skurtveit S, Vangen S, Vollset SE, et al. Effects of preconceptional paternal drug exposure on birth outcomes: cohort study of 340000 pregnancies using Norwegian population-based databases. British journal of clinical pharmacology. 2013;75(4):1134-41.

76. Fukutani K, Ishida H, Shinohara M, Minowada S, Niijima T, Hijikata K, et al. Suppression of spermatogenesis in patients with Behcet's disease treated with cyclophosphamide and colchicine. Fertility and sterility. 1981;36(1):76-80.

77. Rabelo-Junior CN, Bonfa E, Carvalho JF, Cocuzza M, Saito O, Abdo CH, et al. Penile alterations with severe sperm abnormalities in antiphospholipid syndrome associated with systemic lupus erythematosus. Clinical rheumatology. 2013;32(1):109-13.

78. Grunnet E, Nyfors A, Hansen KB. Studies of human semen in topical corticosteroid-treated and in methotrexate-treated psoriatics. Dermatologica. 1977;154(2):78-84.

79. Weber-Schoendorfer C, Hoeltzenbein M, Wacker E, Meister R, Schaefer C. No evidence for an increased risk of adverse pregnancy outcome after paternal low-dose methotrexate: an observational cohort study. Rheumatology. 2014;53(4):757-63.

80. Frank L, Lichtman H, Biro L, Petrou P. Experiences with methotrexate in psoriasis. Dermatologica. 1968;137(2):87-96.

81. Perry WH. Methotrexate and teratogenesis. Archives of dermatology. 1983;119(11):874-5.

82. Lamboglia F, D'Inca R, Oliva L, Bertomoro P, Sturniolo GC. Patient with severe Crohn's disease became a father while on methotrexate and infliximab therapy. Inflammatory bowel diseases. 2009;15(5):648-9.

83. Griggs LR, Schwartz DA. Successful paternity of a healthy child while taking methotrexate for Crohn's disease. The American journal of gastroenterology. 2006;101(12):2893-4.

84. Di Paolo MC, Paoluzi OA, Pica R, lacopini F, Crispino P, Rivera M, et al. Sulphasalazine and 5aminosalicylic acid in long-term treatment of ulcerative colitis: report on tolerance and side-effects. Digestive and liver disease : official journal of the Italian Society of Gastroenterology and the Italian Association for the Study of the Liver. 2001;33(7):563-9.

85. Freeman JG, Reece VA, Venables CW. Sulphasalazine and spermatogenesis. Digestion. 1982;23(1):68-71.

86. Hudson E, Dore C, Sowter C, Toovey S, Levi AJ. Sperm size in patients with inflammatory bowel disease on sulfasalazine therapy. Fertility and sterility. 1982;38(1):77-84.

87. Kjaergaard N, Christensen LA, Lauritsen JG, Rasmussen SN, Hansen SH. Effects of mesalazine substitution on salicylazosulfapyridine-induced seminal abnormalities in men with ulcerative colitis. Scandinavian journal of gastroenterology. 1989;24(7):891-6.

88. Toovey S, Hudson E, Hendry WF, Levi AJ. Sulphasalazine and male infertility: reversibility and possible mechanism. Gut. 1981;22(6):445-51.

89. Riley SA, Lecarpentier J, Mani V, Goodman MJ, Mandal BK, Turnberg LA. Sulphasalazine induced seminal abnormalities in ulcerative colitis: results of mesalazine substitution. Gut. 1987;28(8):1008-12.

90. Cosentino MJ, Chey WY, Takihara H, Cockett AT. The effects of sulfasalazine on human male fertility potential and seminal prostaglandins. The Journal of urology. 1984;132(4):682-6.

91. Heineman MJ, Dony JM, Rolland R. Salicylazosulfapyridine and male infertility. European journal of obstetrics, gynecology, and reproductive biology. 1981;12(5):297-303.

92. Levi AJ, Fisher AM, Hughes L, Hendry WF. Male infertility due to sulphasalazine. Lancet. 1979;2(8137):276-8.

93. McIntyre PB, Lennard-Jones JE. Reversal with balsalazide of infertility caused by sulphsalazine. Br Med J (Clin Res Ed). 1984;288(6431):1652-3.

94. Ragni G, Bianchi Porro G, Ruspa M, Barattini G, Lombardi C, Petrillo M. Abnormal semen quality and low serum testosterone in men with inflammatory bowel disease treated for a long time with sulfasalazine. Andrologia. 1984;16(2):162-7. 
95. Toth A. Reversible toxic effect of salicylazosulfapyridine on semen quality. Fertility and sterility. 1979;31(5):538-40.

96. Zelissen PM, van Hattum J, Poen H, Scholten P, Gerritse R, te Velde ER. Influence of salazosulphapyridine and 5 -aminosalicylic acid on seminal qualities and male sex hormones. Scandinavian journal of gastroenterology. 1988;23(9):1100-4.

97. Wu FC, Aitken RJ, Ferguson A. Inflammatory bowel disease and male infertility: effects of sulfasalazine and 5 -aminosalicylic acid on sperm-fertilizing capacity and reactive oxygen species generation. Fertility and sterility. 1989;52(5):842-5.

98. Cann PA, Holdsworth CD. Reversal of male infertility on changing treatment from sulphasalazine to 5-aminosalicylic acid. Lancet. 1984;1(8386):1119.

99. Chatzinoff M, Guarino JM, Corson SL, Batzer FR, Friedman LS. Sulfasalazine-induced abnormal sperm penetration assay reversed on changing to 5 -aminosalicylic acid enemas. Digestive diseases and sciences. 1988;33(1):108-10.

100. Collen MJ. Azulfidine-induced oligospermia. The American journal of gastroenterology. 1980;74(5):441-2.

101. Delaere KP, Strijbos WE, Meuleman EJ. Sulphasalazine-induced reversible male infertility. Acta Urol Belg. 1989;57(1):29-33.

102. Grieve J. Male infertility due to sulphasalazine. Lancet. 1979;2(8140):464.

103. Shaffer JL, Kershaw A, Berrisford MH. Sulphasalazine-induced infertility reversed on transfer to 5-aminosalicylic acid. Lancet. 1984;1(8388):1240.

104. Tobias R, Sapire KE, Coetzee T, Marks IN. Male infertility due to sulphasalazine. Postgraduate medical journal. 1982;58(676):102-3.

105. Traub Al, Thompson W, Carville J. Male infertility due to sulphasalazine. Lancet. 1979;2(8143):639-40.

106. Margalioth EJ, Navot D, Beyth Y. Diagnosis of drug-related male infertility by zona-free hamster egg sperm penetration assay. Lancet. 1985;2(8449):275.

107. Iglesias-cortit JL, Paz JL, Ballesca JL, Valles A, Iglesias-guiu J, Freixa R, et al. Effects of sulphasalazine, lysine acetylsalicylate and flurbiprofen on human spermatozoa. Advances in contraceptive delivery systems : CDS. 1985(1):92-6.

108. Freixa R, Rosello Catafau J, Gelpi E, Iglesias Cortit JL, Ballesca JL, de Paz JL, et al. Comparative study of antiinflammatory drugs and sulphasalazine in relation to prostaglandin $\mathrm{E}$ and 19 hydroxylated prostaglandin E levels and human male fertility. Prostaglandins, leukotrienes, and medicine. 1984;16(3):359-69. 